\begin{tabular}{|c|c|}
\hline & Volume \& Issues Obtainable at The Women University Multan \\
\hline
\end{tabular}

\title{
An Examination of the Relationship between Depression, Loneliness, and Sociability in the Old Aged Community of District DG Khan
}

\author{
Ayesha Abid', Khalil Ahmad², Mussarat Hussain ${ }^{3}$ \\ ${ }^{1}$ Institute of Social \& Cultural Studies, University of the Punjab, Lahore \\ ${ }^{2}$ Professor, Institute of Social \& Cultural Studies, University of Punjab, Lahore \\ ${ }^{3}$ Lecturer, Department of Sociology, University of Sargodha Bhakkar Campus \\ ARTICLE DETAILS

\section{ABSTRACT}

\section{History:}

Received:

Review:

Accepted:

August 16, 2021

October 20, 2021

November 08,2021

Available Online:November 08,2021

\section{Keywords:}

Loneliness, Depression, Sociability, Elderly, Prevalence

\section{DOI:}

10.52700/assap.v2i2
The present study was aimed to assess depression, loneliness, and sociability among elderly people, as well as to assess the prevalence of elder abuse, and to draw conclusions about the quality of life and its effect on elderly health in DG Khan's Tehsil Taunsa Sharif. In this regard, the study was preceded by using a quantitative research design. A sample of 200 elderly people was surveyed (both male and female at the time of the interview). The elderly were interviewed with the help of their relatives. The interview schedule was used to collect data. Analysis of the data was carried out using the SPSS Software 21. The data was analyzed using the univariate regression test and the multivariate binary logistic regression test. The results of the binary logistic regression test showed that sociability gets decreased as people age, depression and loneliness increase. Moreover, advancement in the education of the respondents led to a decrease in respondents' depression, loneliness and sociability. Life satisfaction was affected by health and social support in different ways, depending on the person major determinants, such as education and nationality, as well as savings, income, frequency of contact with their children or relatives and neighbors, the number of known and trusted people in a village or city, as well as physical and mental health, were unaffected by age and gender. Additionally, it is recommended that in addition to primary care, health stakeholders should focus on health programs for the health promotion of the elderly to protect the elderly from serious health problems, especially mental health problems.

(C) 2021 The Authors, Published by WUM. This is an Open Access Article under the Creative Common Attribution Non Commercial 4.0 
Corresponding author's email address: mussarat.hussain@uos.edu.pk

\section{Introduction}

Globally, different scientific studies had been conducted to enlighten the importance of social support for older populations for decades. Poor life satisfaction has been linked to a lack of positive social support (Rioux, 2005). Support from friends and family after major SLEs can also act as a buffer between stress and wellbeing (Chronister et al., 2013). According to Hsu (2012), depressive symptoms are lessened by changes in social support over time, as well as by stressors in life. As a result, if mood and depression are alleviated by increasing social support, it is reasonable to assume that life satisfaction will increase as a result over time (Stice et al 2004). Loneliness has been examined from a variety of angles because there is no precise definition. It's even more difficult to understand the definition when it's accompanied by other related concepts (Tikkainen and Heikkinen, 2004). Loneliness is defined as being alienated from others in the most basic sense. But isolation is also seen as an opportunity for "self-improvement and flexibility" if it is used properly. Aloneness, a state of being isolated from everyone else but not feeling lonely, is also a possibility (Karnick, 2005). Loneliness can have a negative effect on both physical and mental health. According to Berg et al. (2006), an increase in alcohol consumption, and physical ailments have all been linked to it. Seniors are becoming more prevalent in Pakistan, which is one of the Asian nations where this is happening. In 1951, Pakistan's mature population was 1.921 million people, and by 1998, it had grown to 7.338 million people (males 3.990 and females 3.348) (GoP, 1998). Reviews on maturing in Pakistan tend to be brief due to financial constraints, and only a few studies have been conducted to highlight the needs and issues of maturity. Many issues have arisen in Pakistan as a result of changing family patterns, urbanization, and the relocation of young people to other countries. According to the United Nations, there are currently 11.5 million mature Pakistanis out of a total population of 185 million, and that number is expected to grow to 50 million by 2050 . In Pakistan, the mature population makes up $6 \%$ of the total population (UNDESA, 2009). To identify research gaps, a thorough literature review was conducted, taking into account both the international and Pakistani contexts. This helped to identify the most critical research gaps. So forth, the researcher is interested in finding out how satisfied elders are in their communities and institutions, as well as identifying the factors that can help make elders' lives more contented as well as peaceful. On top of all that, this investigation has gathered data on the future approach and rational arrangement of activities for older people in Pakistan, as less work has been done on this topic throughout Pakistan, but most notably within the province of Punjab. The purpose of this study is to determine the impact of quality of life on elder health because there is a growing awareness around the world that some older people are victims of rough treatment, neglect, or abuse.

\subsection{Objectives of the Study}

i. To assess the prevalence level of depression, loneliness, and sociability among the elderly;

ii. To measure the relationship of different factors contributing towards the quality of life of the elderly;

iii. To determine the relationship between quality of life and elderly quality of life. 


\subsection{Research Questions}

Following research questions were focused to find the major factors that affect life satisfaction among the elderly of D.G Khan. There are two research questions focused on, as follows:

1. What are the effects of health, and social support on the life satisfaction of the elderly, considering five different age groups; 60- 65; 66-70; 71-75; 76-80; 81 and above? This question was created to examine how loneliness, depression, and social ability which together form life satisfaction differ according to the age differences because of health and social support.

2. What are the most influential determinants of life satisfaction among the elderly? This question was to understand which factors between health and social supports have the most significant effects on life satisfaction between elderly.

\section{Research Design \& Methodology}

A quantitative approach was taken in the study. The purpose of the study was to determine the prevalence of depression, loneliness, and sociability among the elderly population. 2,872,201 people were living in this district according to the 2017 Pakistan census, and 85,599 of them were 60 and older, with 47,385 males and 38,214 females. Using a specially designed interview schedule, a house-to-house survey was conducted in Tehsil Taunsa Sharif District D.G Khan to collect the data. The study's population consisted of people over the age of 60 who lived in the community. Only older men and women who lived in tehsil Taunsa Sharif, District DG khan, were considered. The study's population consisted of people over the age of 60 who lived in the community. Only older men and women from the tehsil Taunsa Sharif district of D.G. Khan in the south of Punjab were selected. As a result of the poverty and lack of infrastructure in this particular district, we chose to interview respondents from this area. Accordingly, the study was restricted to the following categories: Participants' ages were restricted to women and men aged 60 and older.

Researchers focused on factors that contribute to elderly people's life satisfaction. Depression, loneliness, and sociability are some of these factors. The researcher selected respondents using a non-probability sampling technique called purposeful sampling. According to the current study, 200 people aged 60 and older were included in the study's sample. 100 respondents came from the rural areas of D.G. Khan, and 100 came from the urban areas. The study respondents were limited to the Tehsil Taunsa Sharif of district Dera Ghazi Khan in province Punjab of Pakistan. We wanted to know the ground realities and exact factors that contribute to depression, loneliness, sociability, and isolation among the elderly in D.G. Khan. The researcher developed a questionnaire following a thorough literature review. Using simple language ensured that every respondent could easily comprehend the questions. Respondents were interviewed one-on-one in a face-to-face setting by researchers. For example, the first part of the questionnaire asked about elders and their families' demographics and other personal information, while the second part asked about their current living situation in terms of physical, psychological, and social well-being as well as financial well-being as well as satisfaction and autonomy regarding their lives. They were chosen to assess the physical, psychological, social, and financial well-being of the elders in the study. To perform the statistical analysis, SPSS version 21 was used. The 
effects of demographic characteristics, financial support, emotional support, physical health, and psychological health on life satisfaction among the elderly were examined using binary logistic regression analysis. The effects of demographic characteristics, financial support, emotional support, physical health, and psychological health on life satisfaction among the elderly were examined using binary logistic regression analysis. An analysis was performed on three age groups before examining the effects of demographic characteristics, social support, and health for all elderly. Finally, the effects of the independent variables on depression, loneliness, and sociability among the elderly were examined.

\subsection{Reliability and Pilot testing of the instrument}

The tool of data collection was developed by the researcher with the help of a supervisor. The scale for measuring depression comprised of 15 items, along with this a 20 item scale was developed to determine loneliness and to determine other factors. For pilot testing of the scale, the data was collected from 10 respondents settled in the rural area and also from 10 respondents settled in the urban area. After the pre-testing few questions were revised according to the responses of the individuals and non-responsive questions were removed. The data was coded and entered in SPSS 21 for the reliability analysis of the scale. The reliability coefficient of the questionnaire for GDS-15 for pilot testing was determined by applying the Cronbach alpha reliability method and its value was 0.80 and value for loneliness scale found $\propto=0.78$.

Table 1: Mean, Standard Deviation and Reliability Coefficient for responding to GDS15 Scale

\begin{tabular}{lll}
\hline Mean & Standard Deviation & Cronbach Alpha Reliability Coefficient \\
94.27 & 5.54 & 0.80 \\
\hline
\end{tabular}

Table 2: Mean, Standard Deviation and Reliability Coefficient for responding to loneliness scale

\begin{tabular}{lll}
\hline Mean & Standard Deviation & Cronbach Alpha Reliability Coefficient \\
90.75 & 5.15 & 0.78 \\
\hline
\end{tabular}

\subsection{Operationalization of the Variable}

The variables were operationalized to measure the distribution of populations regarding their characteristics, financial support, emotional support, physical health, and psychological health. These personal characteristics included education, religion, nationality, and employment status. Components of financial supports included income, remittances, income from other sources, saving, household income. Emotional supports were related to children in a house, the distance of children from a house, the frequency of interaction and communication with children, relative in a house, the frequency of interaction and communication with a relative, a distance of neighbor, and the frequency of interaction and communication with neighbors. Physical health referred to only perceived health. GDS-15 scale for measuring depression was assessed regarding fifteen elements of subjective depression: satisfaction, activities and interests, happiness, staying at home, feeling wonderful, living ability, energy, the emptiness of life, activities, fear, self-acceptance, selfcontrol, self-confidence, self-sympathizing feelings for others' difficulties, self-happiness for 
helping others, self-willingness to help others and self-belief about receiving cares from family members.

\section{Results \& Analysis}

The following section of the study explains the major findings of the study variables which represent that how loneliness, depression $\mid \&$ sociability were presented among study participants.

Table 3: Frequency distribution, standard deviation (S.D), Variance, and significance respondents on Geriatric Depression Scale (GDS-15) $(\mathbf{n = 2 0 0})$

\begin{tabular}{|c|c|c|c|c|c|c|c|}
\hline \multirow[t]{3}{*}{ Description } & \multicolumn{4}{|c|}{ Categories } & \multirow{3}{*}{ S. D } & \multirow{3}{*}{ Variance } & \multirow{3}{*}{ Sig.* } \\
\hline & \multicolumn{2}{|l|}{ Yes } & \multicolumn{2}{|l|}{ No } & & & \\
\hline & $\mathbf{F}$ & $\%$ & $\mathbf{F}$ & $\%$ & & & \\
\hline satisfied with life & 50 & 25.0 & 90 & 75.0 & .140 & .020 & .001 \\
\hline drop activities and interests & 67 & 33.5 & 133 & 66.5 & .499 & .249 & .706 \\
\hline happy most of the time & 68 & 34.0 & 132 & 66.0 & .337 & .113 & .038 \\
\hline prefer to stay at home & 72 & 35.8 & 128 & 64.2 & .438 & .191 & .026 \\
\hline in good spirit most of the time & 75 & 37.5 & 125 & 62.5 & 1.141 & 1.302 & .130 \\
\hline it is wonderful to alive now & 79 & 39.5 & 121 & 60.5 & 1.766 & 3.118 & .459 \\
\hline feeling full of energy & 86 & 43.0 & 114 & $\mathbf{5 7 . 0}$ & 2.327 & 5.413 & .991 \\
\hline feel that your life is happy & 89 & 44.5 & 111 & 55.5 & 1.743 & 3.037 & .111 \\
\hline get bored & 94 & 47.0 & 106 & $\mathbf{5 3 . 0}$ & 1.757 & 3.088 & .755 \\
\hline something bad is going to happen & 98 & 49.0 & 102 & 51.0 & 2.147 & 4.608 & .046 \\
\hline feel helpless & 101 & 50.5 & 99 & 49.5 & .359 & .129 & .049 \\
\hline have more problem with memory & 106 & $\mathbf{5 3 . 0}$ & 94 & 47.0 & 1.215 & 1.475 & .332 \\
\hline situation is hopeless & 115 & 57.5 & 85 & 42.5 & .466 & .217 & .347 \\
\hline $\begin{array}{l}\text { most people are better off than you } \\
\text { are }\end{array}$ & 118 & 59.0 & 82 & 41.0 & .417 & .174 & .459 \\
\hline feel worthless the way you are now & 120 & 60.0 & 80 & 40.0 & .313 & .098 & .005 \\
\hline
\end{tabular}

*Significance level is measured at 0.05

The aforementioned table results show that the frequency distribution, standard deviation (S.D), variance, and significance of the elderly on the geriatric depression scale. The analysis of the data showed that on the GDS-15 scale few elements were significant with the elderly. 
Among the significant elements, there was the life satisfaction of the elderly depicting .001 pvalue, elderly happy most of the time was significant at .038 level. Preference by the elderly to stay at home was also significant with the categories. Something bad is going to happen was also significant. It could be because there is a common perception that the increases in age increase the sensitivity of the people in the area. In the elderly where the extremity strength going to decrease the respondents feel helpless because they became dependent on others even for their mobility and that was why the analysis also depicts the same results and this leads them to feel worthless.

Table 4: Odds Ratios of Loneliness among Elderly

\begin{tabular}{|c|c|c|c|c|}
\hline & \multirow[t]{2}{*}{ Sig. } & \multirow[t]{2}{*}{$\operatorname{Exp}(\boldsymbol{\beta})$} & \multicolumn{2}{|c|}{ OR $(95 \% \operatorname{CI})$ for $\operatorname{Exp}(\beta)$} \\
\hline & & & Lower & Upper \\
\hline \multicolumn{5}{|c|}{ Age of Respondents (ref=60 to 65) } \\
\hline $66-70$ & .000 & 1.238 & 1.117 & 1.343 \\
\hline $71-75$ & .001 & 1.287 & 1.154 & 1.463 \\
\hline $76-80$ & .001 & 2.381 & 1.993 & 2.071 \\
\hline 81 and above & .027 & 1.267 & 1.067 & 1.131 \\
\hline \multicolumn{5}{|c|}{ Education (ref= literate) } \\
\hline Illiterate & .000 & 1.432 & 1.143 & 1.989 \\
\hline \multicolumn{5}{|c|}{ Family Size (ref $=7$ and above) } \\
\hline $1-3$ & .000 & 3.307 & 2.040 & 5.362 \\
\hline $4-6$ & .004 & 1.584 & 1.179 & 2.128 \\
\hline \multicolumn{5}{|c|}{ Gender $($ ref $=$ female $)$} \\
\hline Male & .014 & 1.997 & 1.221 & 1.357 \\
\hline \multicolumn{5}{|c|}{ Area (ref= Urban) } \\
\hline Rural & .000 & .636 & .512 & .791 \\
\hline \multicolumn{5}{|c|}{ Like to live (ref= in the gathering) } \\
\hline Alone & .802 & 1.189 & 1.209 & 1.550 \\
\hline \multicolumn{5}{|c|}{ Change of environment (ref $=$ Yes) } \\
\hline No & .098 & 1.946 & 1.524 & 2.484 \\
\hline \multicolumn{5}{|c|}{ Family income $($ ref= 0-5000) } \\
\hline $5001-10000$ & .071 & 1.391 & 0.720 & 1.289 \\
\hline $10001-15000$ & .000 & 1.534 & 1.802 & 1.747 \\
\hline $15001-20000$ & .002 & .656 & 0.490 & 0.877 \\
\hline $20001-25000$ & .001 & 1.494 & .796 & .867 \\
\hline 25001- above & .003 & .325 & .344 & .403 \\
\hline \multicolumn{5}{|c|}{ Family system (ref= Nuclear) } \\
\hline Joint & .000 & .716 & .498 & 1.028 \\
\hline Extended & .005 & .524 & .384 & .716 \\
\hline \multicolumn{5}{|c|}{ Son live with you $($ ref = Yes $)$} \\
\hline No & .997 & 1.772 & 1.628 & 1.949 \\
\hline \multicolumn{5}{|c|}{ Opinion in family matters (ref= Yes) } \\
\hline No & .441 & 1.713 & 1.534 & 1.911 \\
\hline
\end{tabular}

The above given table results depict the odds of loneliness among the elderly. The analysis of the collected data indicated that the probability of loneliness was different at a different level of categories among the variable and along with this the significance level was also different 
based on the significance with the variable examined. The age of respondents was measured for determining the level of loneliness among the different age groups. The age group 61 to 65 was assigned the value 1 and was in the reference category. Results showed that the categories were significantly associated and showed that with the increase in the age of the elderly, loneliness decreases. When we compare the odds of age group 76 to 80 having odds $=1.993$ lower value and 2.071 upper value at .001 significant with the odds of age group 71 to 75 having 1.154 lower value and 1.463 upper value, the investigator concluded by keeping in view the odds that with the increase in the age the loneliness tends to decrease. In comparing the literacy level of the respondents, the literate was taken as reference and illiterate were analyzed the result showed that there is a significant association at $0.000 \mathrm{p}$ values but the odds of illiterate respondents (lower value $=1.143$, upper value $=1.989$ ) showed that the loneliness decreases with the increase in the education level. The family size was analyzed to know the respondent's loneliness and the group of having 7 and above persons were compared with the category of having 1 to 3 members. The comparison concluded that the odds (lower value $=2.040$, upper value $=5.362$ ) of the family having 3 members were higher as compared to that of having 7 and above. The results showed that the increase in the family size decreases the chances of loneliness. In comparing the gender of the respondents, the female was taken as reference and male was analyzed the result showed that there is a significant association at 0.000 p-values but the odds of male respondents (lower value $=1.221$, upper value $=1.357$ ) showed that the loneliness level was different among the gender and was lower in female as compared with male. In comparing the area of the respondents, the urban was taken as reference and rural was analyzed, the result showed that there is a significant association at $0.000 \mathrm{p}$-values but the odds of rural respondents (lower value $=.512$, upper value $=.791$ ) showed that the loneliness was 51 to $79 \%$ less among the rural respondents as compared with urban respondents. In comparing the like to live of the respondents, the like to live in gathering category was taken as reference and alone was analyzed, the result showed that there is no significant association at $0.802 \mathrm{p}$-values but the odds of rural respondents (lower value $=1.524$, upper value $=2.484$ ) showed that the loneliness level has nothing to do with the elderly liking of life. In comparing the change of environment of the respondents, the yes category was taken as reference and No was analyzed, the result showed that there is no significant association at $0.098 \mathrm{p}$-values but the odds of respondents saying No was (lower value $=1.524$, upper value $=2.484$ ) showed that the loneliness level has nothing to do with the elderly change of environment. The income level of respondents was compared, low level income which was categorized into 0 to 5000 and high level 25000 and above were compared. The odds (lower value $=0.344$, upper value $=0.403$ ) of the high level of income showed that the loneliness was 34 to $40 \%$ less among the age group with the high level of income as compared with the low level of income at 0.003 significance level. The family structure was compared in this analysis. The nuclear family was compared with the extended family and the odds (lower value $=0.384$, upper value $=0.716$ ) showed that the loneliness was 38 to $71 \%$ low among the elderly residing in the extended family as compared to that of the nuclear family system. In comparing the son living with the respondents, the yes category was taken as reference and No was analyzed, the result showed that there is no significant association at $0.998 \mathrm{p}$-values but the odds of respondents saying No was (lower value $=1.628$, upper value=1.949) showed that the loneliness level has nothing to do with the son living with the respondent. In comparing the opinion in family matters of the respondents, the yes category was taken as reference and No was analyzed, the result showed that there is no significant association at $0.441 \mathrm{p}$-values but the odds of respondents saying No was (lower value $=1.534$, upper value $=1.911$ ) showed that the loneliness level has nothing to do with the elderly opinion in the family matters. 
Table 5: Odds Ratios of Depression among Elderly

\begin{tabular}{|c|c|c|c|c|}
\hline & \multirow[t]{2}{*}{ Sig. } & \multirow[t]{2}{*}{$\operatorname{Exp}(\beta)$} & \multicolumn{2}{|c|}{ OR $(95 \% \mathrm{CI})$ for $\operatorname{Exp}(\beta)$} \\
\hline & & & Lower & Upper \\
\hline \multicolumn{5}{|c|}{ Age of Respondents (ref=60 to 65) } \\
\hline $66-70$ & .213 & 1.275 & 1.136 & 1.549 \\
\hline $71-75$ & .107 & 1.259 & 1.149 & 1.353 \\
\hline $76-80$ & .001 & 2.572 & 2.218 & 2.667 \\
\hline 81 and above & .124 & 1.712 & 1.293 & 1.696 \\
\hline \multicolumn{5}{|c|}{ Education (ref= literate) } \\
\hline Illiterate & .005 & 1.417 & 1.219 & 1.408 \\
\hline \multicolumn{5}{|c|}{ Family Size (ref $=7$ and above) } \\
\hline $1-3$ & .035 & 2.286 & 2.551 & 2.337 \\
\hline $4-6$ & .040 & 1.715 & 2.090 & 1.889 \\
\hline \multicolumn{5}{|c|}{ Gender (ref = female) } \\
\hline Male & .044 & 2.773 & 1.992 & 2.015 \\
\hline \multicolumn{5}{|c|}{ Rural/urban (ref= Urban) } \\
\hline Rural & .010 & .435 & .421 & .684 \\
\hline \multicolumn{5}{|c|}{ Like to live (ref= in gathering) } \\
\hline Alone & .208 & 1.534 & 1.802 & 1.947 \\
\hline \multicolumn{5}{|c|}{ Change of environment (ref= Yes) } \\
\hline No & .987 & 1.893 & 1.644 & 1.548 \\
\hline \multicolumn{5}{|c|}{ Family income $($ ref $=0-5000)$} \\
\hline $5001-10000$ & .473 & 1.504 & 1.682 & 1.522 \\
\hline $10001-15000$ & .043 & 1.695 & 1.125 & 1.077 \\
\hline $15001-20000$ & .008 & .886 & .777 & .718 \\
\hline $20001-25000$ & .025 & 1.098 & 1.328 & 1.243 \\
\hline 25001- above & .006 & .341 & .354 & .440 \\
\hline \multicolumn{5}{|c|}{ Family system (ref= Nuclear) } \\
\hline Joint & .001 & .897 & .784 & 1.553 \\
\hline Extended & .005 & .653 & .636 & .695 \\
\hline \multicolumn{5}{|c|}{ Son live with you $($ ref $=$ Yes) } \\
\hline No & .799 & 1.522 & 1.539 & 1.757 \\
\hline \multicolumn{5}{|c|}{ Opinion in family matters (ref $=$ Yes) } \\
\hline No & .142 & 1.531 & 1.728 & 1.893 \\
\hline
\end{tabular}

The aforementioned table indicates the odds of depression among the elderly. The analysis of the collected data indicated that the probability of depression was different at a different level of categories among the variable and along with this the significance level was also different based on the significance with the variable examined. The age of respondents was measured for determining the level of depression among the different age groups. The age group 61 to 65 was assigned the value 1 and was in the reference category. Results showed that the only category which was significantly associated and showed that with the increase in the age of the elderly, depression decreases. When we compare the odds of age group 76 to 80 having odds $=2.218$ lower value and 2.667 upper value at .001 significant with the odds of age group 60 to 65 taken as the reference value, the investigator concluded by keeping in view the odds that with the increase in the age the depression tends to increase and nothing to do with the 
other age categories of respondents. In comparing the literacy level of the respondents, the literate was taken as reference and illiterate were analyzed the result showed that there is a significant association at $0.05 \mathrm{p}$-value but the odds of illiterate respondents (lower value $=1.219$, upper value $=1.408$ ) showed that the depression decreases with the increase in the education level. The family size was analyzed to know the respondent's depression and the group of having 7 and above persons were compared with the category of having 1 to 3 members. The comparison concluded that the odds (lower value $=2.551$, upper value $=2.337$ ) of the family having 3 members were higher as compared to that of having 7 and above. The results showed that the increase in the family size decreases the chances of depression. In comparing the gender of the respondents, the female was taken as reference and male was analyzed the result showed that there is a significant association at $0.044 \mathrm{p}$-values but the odds of male respondents (lower value $=1.992$, upper value=2.015) showed that the depression level was different among the gender and was lower in female as compared with male. In comparing the area of the respondents, the urban was taken as reference and rural was analyzed, the result showed that there is a significant association at $0.010 \mathrm{p}$-values but the odds of rural respondents (lower value=.421, upper value=.684) showed that the depression was 42 to $68 \%$ less among the rural respondents as compared with urban respondents. In comparing the like to live of the respondents, the like to live in gathering category was taken as reference and alone was analyzed, the result showed that there is no significant association at $0.208 \mathrm{p}$-values but the odds of like to live alone respondents (lower value $=1.802$, upper value $=1.947$ ) showed that the depression level has nothing to do with the elderly liking of life. In comparing the change of environment of the respondents, the yes category was taken as reference and No was analyzed, the result showed that there is no significant association at $0.987 \mathrm{p}$-values but the odds of respondents saying No was (lower value $=1.644$, upper value $=1.548$ ) showed that the depression level has nothing to do with the elderly change of environment. The income level of the respondent was compared, low level income which was categorized into 0 to 5000 and high level 25000 and above were compared. The odds (lower value $=0.354$, upper value $=0.440$ ) of the high level of income showed that the depression was 35 to $40 \%$ less among the age group with the high level of income as compared with the low level of income at 0.006 significance level. The family structure was compared in this analysis. The nuclear family was compared with the extended family and the odds (lower value $=0.636$, upper value $=0.695$ showed that the depression was 63 to $69 \%$ low among the elderly residing in the extended family as compared to that of the nuclear family system. In comparing the son living with the respondents, the yes category was taken as reference and No was analyzed, the result showed that there is no significant association at $0.799 \mathrm{p}$-values but the odds of respondents saying No was (lower value $=1.539$, upper value $=1.757$ ) showed that the depression level has nothing to do with the son living with the respondent. In comparing the opinion in family matters of the respondents, the yes category was taken as reference and No was analyzed, the result showed that there is no significant association at $0.142 \mathrm{p}$-values but the odds of respondents saying No was (lower value $=1.728$, upper value $=1.893$ ) showed that the depression level has nothing to do with the elderly opinion in the family matters. 
Table 6: Odds Ratios of Sociability among Elderly

\begin{tabular}{|c|c|c|c|c|}
\hline & \multirow[t]{2}{*}{ Sig. } & \multirow[t]{2}{*}{$\operatorname{Exp}(\beta)$} & \multicolumn{2}{|c|}{ OR $(95 \% \mathrm{CI})$ for $\operatorname{Exp}(\beta)$} \\
\hline & & & Lower & Upper \\
\hline \multicolumn{5}{|c|}{ Age of Respondents (ref=60 to 65) } \\
\hline $66-70$ & .000 & 1.297 & 1.187 & 1.217 \\
\hline $71-75$ & .002 & 1.199 & 1.254 & 1.563 \\
\hline $76-80$ & .001 & 2.116 & 2.918 & 2.577 \\
\hline 81 and above & .124 & 1.217 & 1.514 & 1.698 \\
\hline \multicolumn{5}{|c|}{ Education (ref= literate) } \\
\hline Illiterate & .005 & 1.490 & .783 & .903 \\
\hline \multicolumn{5}{|c|}{ Family Size (ref $=7$ and above) } \\
\hline $1-3$ & .025 & 1.401 & 1.409 & 1.625 \\
\hline $4-6$ & .006 & 1.557 & 1.754 & 1.747 \\
\hline \multicolumn{5}{|c|}{ Gender (ref $=$ female) } \\
\hline Male & .031 & 1.695 & 1.125 & 1.077 \\
\hline \multicolumn{5}{|c|}{ Rural/urban (ref= Urban) } \\
\hline Rural & .0277 & .454 & .337 & .576 \\
\hline \multicolumn{5}{|c|}{ Like to live (ref $=$ in gathering) } \\
\hline Alone & .003 & 1.534 & 1.032 & 1.987 \\
\hline \multicolumn{5}{|c|}{ Change of environment (ref $=$ Yes) } \\
\hline No & .893 & .897 & .784 & 1.553 \\
\hline \multicolumn{5}{|c|}{ Family income $($ ref $=0-5000)$} \\
\hline $5001-10000$ & .072 & 1.372 & 1.917 & 1.894 \\
\hline $10001-15000$ & .029 & .510 & .430 & .435 \\
\hline $15001-20000$ & .011 & .779 & .763 & .995 \\
\hline $20001-25000$ & .032 & .886 & .777 & .718 \\
\hline 25001- above & .004 & .341 & .337 & .394 \\
\hline \multicolumn{5}{|c|}{ Family system (ref= Nuclear) } \\
\hline Joint & .011 & .976 & .964 & 1.055 \\
\hline Extended & .035 & .521 & .543 & .587 \\
\hline \multicolumn{5}{|c|}{ Son live with you $($ ref $=$ Yes) } \\
\hline No & .991 & 1.895 & 1.717 & 1.831 \\
\hline \multicolumn{5}{|c|}{ Opinion in family matters (ref= Yes) } \\
\hline No & .491 & 1.531 & 1.339 & 1.893 \\
\hline
\end{tabular}

The aforementioned table data depicts that the odds of sociability among the elderly. The analysis of the gathered data indicated that the probability of sociability was different at a different level of categories among the variable and along with this the significance level was also different based on the significance with the variable examined. The age of respondents was measured for determining the level of sociability among the different age groups. The age group 61 to 65 was assigned the value 1 and was in the reference category. Results showed that the only category which was significantly associated and showed that with the increase in the age of the elderly, sociability decreases. When we compare the odds of age group 76 to 80 having odds $=2.918$ lower value and 2.577 upper value at .001 significant with the odds of age group 60 to 65 taken as the reference value, the investigator concluded by keeping in view the odds that with the increase in the age the sociability tends to decrease. In comparing the literacy level of the respondents, the literate was taken as reference and 
illiterate were analyzed the result showed that there is a significant association at $0.05 \mathrm{p}$-value but the odds of illiterate respondents (lower value $=0.783$, upper value $=0.903$ ) showed that the sociability decreases with the increase in the education level. The family size was analyzed to know the respondent's sociability and the group of having 7 and above persons were compared with the category of having 1 to 3 members. The comparison concluded that the odds (lower value $=1.409$, upper value $=1.625$ ) of the family having 3 members were higher as compared to that of having 7 and above. The results showed that the increase in the family size decreases the chances of sociability. In comparing the gender of the respondents, the female was taken as reference and male was analyzed the result showed that there is a significant association at $0.031 \mathrm{p}$-values but the odds of male respondents (lower value $=1.125$, upper value $=1.077$ ) showed that the sociability level was different among the gender and was lower in female as compared with male. In comparing the area of the respondents, the urban was taken as reference and rural was analyzed, the result showed that there is a significant association at $0.027 \mathrm{p}$-values but the odds of rural respondents (lower value $=.337$, upper value $=.576$ ) showed that the sociability was 33 to $57 \%$ less among the rural respondents as compared with urban respondents. In comparing the like to live of the respondents, the like to live in gathering category was taken as reference and alone was analyzed, the result showed that there is no significant association at $0.893 \mathrm{p}$-values but the odds of like to live alone respondents (lower value $=1.032$, upper value $=1.987$ ) showed that the sociability level has nothing to do with the elderly liking of life. In comparing the change of environment of the respondents, the yes category was taken as reference and No was analyzed, the result showed that there is no significant association at $0.893 \mathrm{p}$-values but the odds of respondents saying No was (lower value $=.784$, upper value $=1.553$ ) showed that the sociability level has nothing to do with the elderly change of environment. The income level of the respondent was compared, low-level income which was categorized into 0 to 5000 and high level 25000 and above were compared. The odds (lower value $=0.337$, upper value $=0.394$ ) of the high level of income showed that the sociability was 33 to $39 \%$ less among the age group with the high level of income as compared with the low level of income at 0.004 significance level. The family structure was compared in this analysis. The nuclear family was compared with the extended family and the odds (lower value $=0.543$, upper value $=0.587$ showed that the sociability was 54 to $58 \%$ low among the elderly residing in the extended family as compared to that of the nuclear family system. In comparing the son living with the respondents, the yes category was taken as reference and No was analyzed, the result showed that there is no significant association at $0.991 \mathrm{p}$-values but the odds of respondents saying No was (lower value $=1.717$, upper value=1.831) showed that the sociability level has nothing to do with the son living with the respondent. In comparing the opinion in family matters of the respondents, the yes category was taken as reference and No was analyzed, the result showed that there is no significant association at $0.491 \mathrm{p}$-values but the odds of respondents saying No was (lower value $=1.339$, upper value $=1.893$ ) showed that the sociability level has nothing to do with the elderly opinion in the family matter.

\section{Discussion}

One of the major factors affecting the quality of life of the elderly in Punjab, Pakistan, and Tehsil Taunsa D.G. Khan, in particular, is the state of their health. Researchers found that perceived health and psychological health had a significant impact on elderly people's satisfaction with their lives, according to study. Similar results were found when age differences were taken into account, with health having the greatest impact on life satisfaction for all of the older age groups studied. As a result, health is intertwined with a wide range of 
life factors, including resources, the ability to work, the daily routine, the ability to function in daily life, as well as self-control and self-assurance (Hyde et al, 2003). As a result of improved coping skills and resources, the elderly who live in better health facilities tend to be happier. Life satisfaction is lower among the elderly who have a poorer perception of their health than those who have a better perception of their health. Desperate financial situations and other major life events also contribute to health issues (Yuji,2006). Apart from perceived health and psychological health, the financial situation was found to have the strongest effects on the life satisfaction of the elderly, especially among the elderly aged 80 and older. Abas et al. (2009) stated that saving and income are related to social status. Other factors which significantly affect the life satisfaction of the elderly are, for example, Life-course perspective explains that the interaction between life satisfaction and age is intermediated with a major life event, socio-economic status, family relationship, social status, social rules and others. Major life events refer to retirement, sickness, poor health, loss of a partner, migration of children, and so forth. In a village, an increase in child migration reduces the number of elderly caregivers at home. It may also affect the frequency of contact or interaction between young children and their elderly parents (Gillyardetal.,2013).

\section{Conclusion}

Researchers in Tehsil Taunsa, District Dera Ghazi Khan, Punjab Province, had examined the prevalence of depression, loneliness, and sociability among elderly people in five different age groups. For the study to be successful, two main research questions were addressed. . How do health and social support affect life satisfaction among the elderly in D.G. Khan, considering five different age groups: 60-65, 66-70, 71-75, 76-80 and 81 and older? Health and social support effects on life satisfaction among elders in D.G. Khan were examined using five different age groups. Also, what are the most important determinants of life satisfaction among older people? It was also determined that health and social support had an impact on elderly life satisfaction, regardless of gender. Several hypotheses were included in the study that was based on two different factors. Health and social support were the two factors. Erstens: In the elderly, there is a correlation between depression levels, educational attainment levels, and life satisfaction, according to a hypothesis. To determine the level of depression among different age groups, the age of respondents was measured. It was determined that the age group of 61 to 65 would be assigned a value of 1 and be placed in the reference category When it comes to age, depression decreases as the elderly get older, according to research. There was a significant association between illiteracy and depression when comparing the literacy level of the respondents. The odds of illiterate respondents (lower value $=1.219$, upper value $=1.408$ ) showed that depression decreases with education level. First and foremost, the main hypothesis focuses on the assessment of loneliness and sociability among older adults In this regard, we can say that The results showed a significant correlation between age categories and loneliness and that loneliness decreases with age. Investigators concluded that loneliness tends to decrease with age. Results showed a statistically significant association between literacy level and loneliness, with a $0.000 \mathrm{p}$ value, but the odds of illiteracy (lower value $=1.143$, upper value $=1.989$ ) showed that loneliness decreases as education level increases. In the same way, older people's sociability is assessed by their age and education. Savings, income, the number of known and trusted people, perceived health, and psychological health all have a positive impact on the life satisfaction of older men. Women's perceived health and psychological well-being are also positively correlated with life satisfaction. As a result of their savings and income, they can pay for their daily expenses as well as health care and other dependents such as grandchildren. Better life satisfaction and quality of life are correlated with higher savings 
and income. Life satisfaction is lower in older people who have a poorer perception of their health than in those with a better perception of their health financial difficulties and other major life events are causing health problems. Several factors influenced both mental and physical health. Productivity, self-control, and self-confidence are all negatively impacted by health issues. Due to a decrease in self-confidence, self-control, and work productivity, elderly people with poor health are less likely to be satisfied with their lives.

\section{References}

Abas, M. A., Punpiuing, S., Jirapramutak, T. Tangchonlatip, K., and Leese, M. P. (2009). Psychological wellbeing, physical impairments and rural aging in a developing country setting. Health and Quality of Life Outcomes, 7-66.

Berg, A., Hassing, I., McLearn, L., \& Johansson, G. (2006). What matters for life satisfaction in the oldest-old? Aging Mental Health, 10, 257-263.

Chronister, J., Chou, C. \& Liao, H. (2013). The role of stigma coping and social support in mediating the effect of societal stigma on internalized stigma, mental health recovery, and quality of life among people with serious mental illness. Journal of Community Psychology, 41(5), 582-600. DOI: 10.1002/jcop.21558.

Gilleard, C., \& Higgs, P. (2013). The fourth age and the concept of a 'social imaginary': A theoretical excursions. Journal of Aging Studies, 27, 368-376. DOI: 10.1016/j.jaging.2013.08.004.

GOP (Government of Pakistan, Islamabad). 1998. Population Census Organization Statistical division.

Hsu HC, Jones BL. Multiple Trajectories of Successful Aging of Older and Younger Cohorts. The Gerontologist. 2012. DOI: 10.1093/geront/gns005.

Hyde M., Wiggins RD, Higgs P., Blane, DB. (2003). A measure of the quality of life in early old age: the theory, development and properties of a needs satisfaction model (CASP-19). Aging and Mental Health, 7, 186-194.

Karnick, P. M. (2005) Feeling lonely: Theoretical perspectives. Nursing Science Quarterly 18 (1), 7-12.

Rioux, L. (2005). The well-being of aging people living in their own homes. Journal of Environmental Psychology, 25, 231-243

Stice, E., Ragan, J. \& Randall, P. (2004). Prospective relations between social support and depression: Differential direction of effects for parent and peer support? Journal of Abnormal Psychology, 113(1), 155-159. systematic reviewGeriatric Nursing 36 (2015) 372e380.

Tikainnen, P., \& Heikkinen. (2004). Association between loneliness, depressive symptoms, and perceived togetherness in older people. Journal of Aging and Mental Health, 9, 526-534.

UNDESA (United Nation Department of Economics and Social Affairs). 2009 World Population Prospects: The 2008 Revision. (United Nations: New York,), p. 78.

Yuji, B. 2006. Changing meaning of the elderly in Nan province, northern Thailand: From" khon thao khon kae" to "phu sung ayu". Southeast Asian Studies, 44(3), 321-336 